\title{
A High Efficiency Si Photoanode Protected by Few-Layer $\mathrm{MoSe}_{2}$
}

\author{
Srinivas Vanka, Yongjie Wang, Pegah Ghamari, Sheng Chu, Ayush Pandey, \\ Pallab Bhattacharya, Ishiang Shih, and Zetian Mi*
}

To date, the performance of semiconductor photoanodes has been severely limited by oxidation and photo-corrosion. Here, a report is given on the use of earth-abundant $\mathrm{MoSe}_{2}$ as a surface protection layer for Si-based photoanodes. Large area $\mathrm{MoSe}_{2}$ film was grown on $p^{+}-n$ Si substrate by molecular beam epitaxy. It is observed that the incorporation of few-layer $(\approx 3 \mathrm{~nm})$ epitaxial $\mathrm{MoSe}_{2}$ can significantly enhance the performance and stability of $\mathrm{Si}$ photoanode. The resulting $\mathrm{MoSe}_{2} / p^{+}-n$ Si photoanode produces a lightlimited current density of $30 \mathrm{~mA} \mathrm{~cm}^{-2}$ in $1 \mathrm{M} \mathrm{HBr}$ under $\mathrm{AM} 1.5 \mathrm{C}$ one sun illumination, with a current-onset potential of $0.3 \mathrm{~V}$ versus reversible hydrogen electrode (RHE). The applied bias photon-to-current efficiency (ABPE) reaches up to $13.8 \%$, compared to the negligible ABPE values $(<0.1 \%)$ for a bare Si photoanode under otherwise identical experimental conditions. The photoanode further produced stable voltage of $\approx 0.38 \mathrm{~V}$ versus RHE at a photocurrent density of $\approx 2 \mathrm{~mA} \mathrm{~cm}^{-2}$ for $\approx 14 \mathrm{~h}$ under AM $1.5 \mathrm{C}$ one sun illumination. This work shows the extraordinary potential of two-dimensional transitional metal dichalcogenides in photoelectrochemical application and will contribute to the development of low cost, high efficiency, and highly stable Si-based photoelectrodes for solar hydrogen production. and possess a high level of stability in aqueous solution. To date, however, it has remained challenging, especially for semiconductor photoanodes, to simultaneously meet these demands. Recently, $\mathrm{Fe}_{2} \mathrm{O}_{3},{ }^{[5]}$ $\mathrm{BiVO}_{4},{ }^{[6]} \mathrm{Ta}_{3} \mathrm{~N}_{5},{ }^{[7]} \mathrm{GaP}^{\left[{ }^{[8]}\right.} \mathrm{GaN} / \mathrm{InGaN}^{[9]}$ and $\mathrm{Si}^{[10]}$ have been intensively studied as photoanodes. Among these materials, $\mathrm{Si}$ is a low cost and abundantly available photoabsorber material, with an energy band-gap of $1.12 \mathrm{eV}$, which has advantages such as high carrier mobility and absorption of a substantial portion of sunlight. ${ }^{[4,11]} \mathrm{Si}$, however, is highly prone to photo-corrosion. ${ }^{[10 a, 12]}$ Various surface protection schemes, including the use of $\mathrm{TiO}_{2}$ and $\mathrm{NiO}_{\mathrm{x}}$, have been developed to improve the stability of Si-based photoanodes. ${ }^{[8,13]}$ The use of wide bandgap and/or thick protection layers, however, severely limits the extraction of photo-excited holes, leading to very low photocurrent density and extremely poor applied bias photon-tocurrent efficiency (ABPE) in the range of $1-2 \%$. $[8,10 \mathrm{a}, 12 \mathrm{~b}, 13 \mathrm{~b}, 13 \mathrm{~d}]$ Recently, by using NiFe-LDH catalyst with $\mathrm{Ni} / \mathrm{NiO}_{\mathrm{x}}$ as a protection layer, an ABPE of $\approx 4.3 \%$ has

The ever-increasing demand for energy has inspired intensive research on the development of sustainable and renewable energy sources to diminish our dependence on fossil fuels. ${ }^{[1]}$ PEC water splitting is one of the most promising methods to convert solar energy into storable chemical energy in the form of $\mathrm{H}_{2}$ production, ${ }^{[2]}$ which is a clean and eco-friendly alternative fuel that can be stored, distributed and consumed on demand. ${ }^{[3]}$ A PEC device generally consists of a semiconductor photocathode and photoanode, which collect photo-generated electrons and holes to drive $\mathrm{H}_{2}$ and $\mathrm{O}_{2}$ evolution reaction, respectively. ${ }^{[4]}$ For practical application, it is essential that the semiconductor photoelectrodes can efficiently harvest sunlight, are of low cost,

S. Vanka, Y. Wang, A. Pandey, Prof. P. Bhattacharya, Prof. Z. Mi Department of Electrical Engineering and Computer Science University of Michigan

Ann Arbor, 1301 Beal Avenue, Ann Arbor, MI 48109, USA

E-mail: ztmi@umich.edu

S. Vanka, Dr. S. Chu, P. Ghamari, Prof. I. Shih, Prof. Z. Mi

Department of Electrical and Computer Engineering

McGill University

3480 University Street, Montreal, Quebec H3A 0E9, Canada

DOI: 10.1002/solr.201800113 been demonstrated for Si photoanodes, ${ }^{[14]}$ which however, still lags significantly behind those $(\approx 10-15 \%)$ for Si-based photocathodes. ${ }^{[10 \mathrm{c}, 15]}$

Studies have shown that earth-abundant two-dimensional (2D) transition metal dichalcogenides (TMDC), including $\mathrm{MoS}_{2},{ }^{[16]} \mathrm{WSe}_{2},{ }^{[17]} \mathrm{MoSe}_{2}{ }^{[17 \mathrm{~b}, 18]}$ and $\mathrm{WS}_{2},{ }^{[19 a]}$ possess remarkable properties for PEC application. The edge states of monolayer TMDC can provide catalytic sites for $\mathrm{H}_{2}$ evolution reaction (HER), ${ }^{[19]}$ and TMDCs have also been employed as photoanodes for oxidation reaction. ${ }^{[16,17 \mathrm{~b}, 17 \mathrm{~d}, 18,20]}$ Recent first principles calculations have further revealed that perfect 2D TMDCs are chemically inert, ${ }^{[21]}$ and their excellent stability in acidic electrolyte has also been reported. ${ }^{[22]}$ Due to the van der Waals bonds, high quality interface can be formed when 2D TMDC is deposited on Si surface, which can offer an effective means to passivate the $\mathrm{Si}$ surface and minimize surface recombination. ${ }^{[23]}$ To date, however, there have been no reports on the use of 2D TMDCs as a surface protection layer for semiconductor photoanodes. This has been limited, to a large extent, by the lack of controllable synthesis process of 2D TMDCs. The commonly used exfoliation process is not suited to 
produce uniform TMDCs with controlled thickness and highquality interface on a large area wafer. ${ }^{[24 a, 24 b]}$ Alternatively, the growth/synthesis of 2D TMDCs using bottom-up approaches such as chemical vapor deposition (CVD) and molecular beam epitaxy (MBE) have been intensively studied. ${ }^{[24]}$ The latter method, which utilizes ultrahigh vacuum (UHV) environment, is highly promising to produce high purity and controllable film thickness. ${ }^{[24 a, 24 b, 25]}$

Herein, we have investigated the MBE growth of large area $\mathrm{MoSe}_{2}$ film on $p^{+}-n$ Si substrate and have further studied the PEC performance of $\mathrm{Si}$ photoanode with $\mathrm{MoSe}_{2}$ protection layers of varying thicknesses. It is observed that the incorporation an ultrathin $(\approx 3 \mathrm{~nm})$ epitaxial $\mathrm{MoSe}_{2}$ can significantly enhance the performance and stability of $p^{+}-n$ $\mathrm{Si}$ photoanode. The $\mathrm{MoSe}_{2} / p^{+}-n \mathrm{Si}$ photoanode produces a nearly light-limited current density of $\approx 30 \mathrm{~mA} \mathrm{~cm}^{-2}$ in $1 \mathrm{M}$ $\mathrm{HBr}$ under AM 1.5G one sun illumination, with a currentonset potential of $0.3 \mathrm{~V}$ versus RHE. The ABPE reaches up to $13.8 \%$, compared to the negligible ABPE values $(<0.1 \%)$ of bare Si photoanode. Moreover, nearly $100 \%$ hole injection efficiency is achieved under a relatively low voltage of $<0.6 \mathrm{~V}$ versus RHE. The chronovoltammetry analysis for the photoanode shows a stable voltage of $\approx 0.38 \mathrm{~V}$ versus $\mathrm{RHE}$ for $\approx 14 \mathrm{~h}$ at $\approx 2 \mathrm{mAcm}^{-2}$. The effect of $\mathrm{MoSe}_{2}$ layer thickness on the PEC performance is also investigated. This work shows the extraordinary potential of 2D TMDC in PEC application and promises a viable approach for achieving high efficiency $\mathrm{Si}$ based photoanodes.

Schematically shown in Figure 1a, $\mathrm{MoSe}_{2}$ films were grown on $p^{+}-n$ Si substrate using a Veeco GENxplor MBE system. The fabrication of $p^{+}-n$ Si wafer is described in Supporting Information, Section 1. As described in Experimental Section, the MBE growth of $\mathrm{MoSe}_{2}$ thin film results in $2 \mathrm{H}$ structure, ${ }^{[24 \mathrm{~b}]}$ which is schematically shown in Figure 1a. The energy band diagram of the $\mathrm{MoSe}_{2} / p^{+}-n \mathrm{Si}$ photoelectrode is illustrated in Figure 1b. Photo-excited holes can tunnel through the thin $\mathrm{MoSe}_{2}$ protection layer to participate in oxidation reaction, while photo-excited electrons from $\mathrm{Si}$ migrate towards the counter electrode to participate in $\mathrm{H}_{2}$ evolution reaction. The $\mathrm{MoSe}_{2}$ layer also suppresses surface recombination. ${ }^{[23 \mathrm{~b}]}$ It is seen that the thickness of $\mathrm{MoSe}_{2}$ is critical: it needs to be optimally designed and synthesized to protect the Si surface against photo-corrosion and oxidation without compromising the hole transport and extraction.

Properties of $\mathrm{MoSe}_{2}$ grown on $\mathrm{Si}$ wafer by $\mathrm{MBE}$ are characterized using X-ray photoelectron spectroscopy (XPS), atomic force microscopy (AFM), and micro-Raman spectroscopy. We have first analyzed the composition of $\mathrm{MoSe}_{2}$ layers by using XPS measurement (Thermo Scientific K-Alpha XPS system with a monochromatic $\mathrm{Al} \mathrm{Ka}$ source $(\mathrm{h} v=1486.6 \mathrm{eV}))$. The binding energy of carbon $(284.58 \mathrm{eV})$ was used as a reference peak position for the measurements. Figure 2a shows two peaks located at 229.2 and $232.4 \mathrm{eV}$ which originated from Mo $3 \mathrm{~d}_{5 / 2}$ and Mo $3 \mathrm{~d}_{3 / 2}$ orbitals, respectively, confirming the existence of $\mathrm{Mo}^{4+} \cdot{ }^{[26]}$ Shown in Figure $2 \mathrm{~b}$, a single doublet of Se $3 \mathrm{~d}_{5 / 2}$ at $54.9 \mathrm{eV}$ and $\mathrm{Se} 3 \mathrm{~d}_{3 / 2}$ at $55.6 \mathrm{eV}$ can be observed, corresponding to the oxidation state of -2 for Se. ${ }^{[24 b, 24 e, 26]}$ These results confirm the formation of $\mathrm{MoSe}_{2}$ on the Si wafer. Micro-Raman spectroscopy was carried out using a $514 \mathrm{~nm}$ (a)

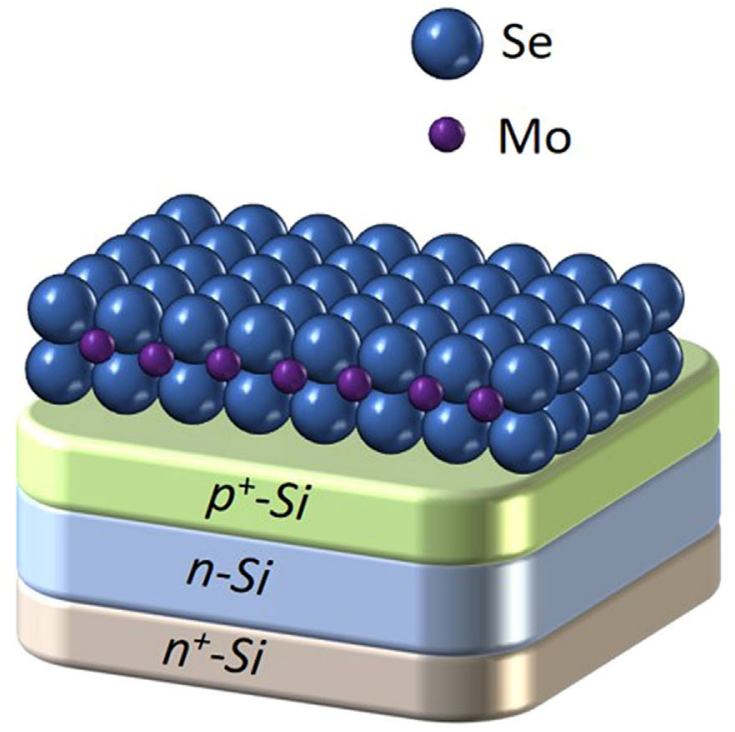

(b)

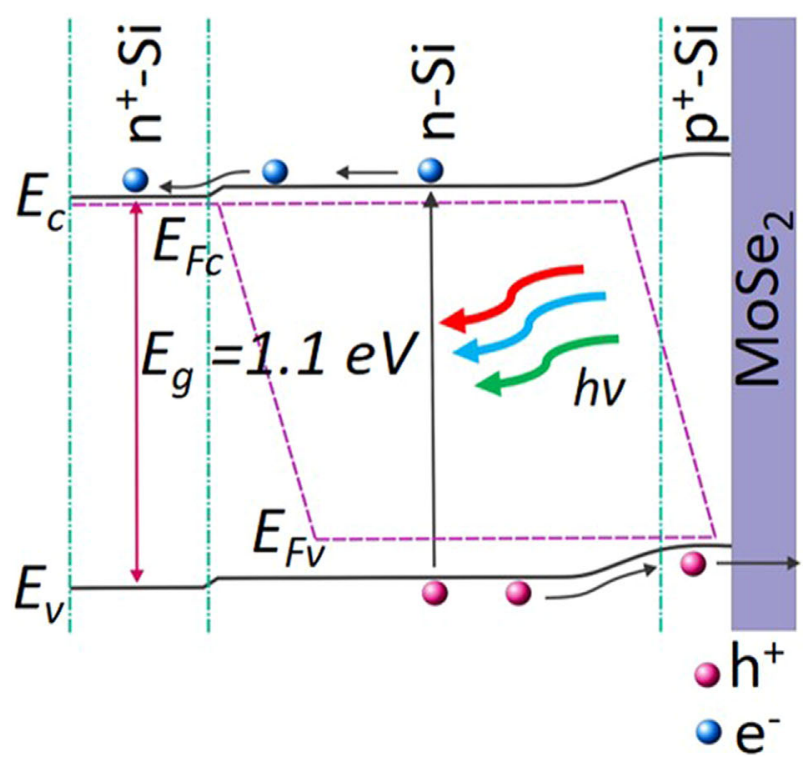

Figure 1. Design of $\mathrm{MoSe}_{2} / p^{+}-n$ Si photoanode. a) Schematic illustration of $p^{+}-n$ Si photoanode protected by few-layer $2 \mathrm{H} \mathrm{MoSe} e_{2}$. Dark blue and purple colored atoms denote Se and Mo, respectively. b) Schematic of the energy band diagram of $\mathrm{MoSe}_{2} / p^{+}-n$ Si photoanode under AM 1.5G light illumination.

argon ion laser as the excitation source. Illustrated in Figure 2c, emission peaks at $163.02,235.67,281.89$, and $346.18 \mathrm{~cm}^{-1}$ have been identified, which correspond to $E_{1 g}, A_{1 g}, E_{2 g}{ }^{1}$, and $A_{2 u}{ }^{2}$ modes, respectively. The most prominent peaks are $\mathrm{A}_{1 \mathrm{~g}}$ and $\mathrm{E}_{2 \mathrm{~g}}{ }^{1}$ modes, which are related to the out-of-plane vibration and in-plane vibration, respectively. These Raman modes, unique to $2 \mathrm{H}-\mathrm{MoSe}_{2}$, have been observed in previous reports and suggest the formation of $2 \mathrm{H}$-phase $\mathrm{MoSe}_{2}$ on $\mathrm{Si}$ wafer. ${ }^{[27]}$ Shown in 
Figure $2 \mathrm{~d}$ is the AFM image of $\mathrm{MoSe}_{2}$ film ( $\approx 3 \mathrm{~nm}$ thick) grown on Si (also see Supporting Information, Section 3).

We have subsequently investigated the PEC performance of $\mathrm{MoSe}_{2} / p^{+}-n$ Si photoanode. The linear scan voltammogram (LSV) of $\mathrm{MoSe}_{2} / p^{+}-n \mathrm{Si}$ photoanodes with various $\mathrm{MoSe}_{2}$ thicknesses is shown in Figure 3a under both dark and illumination conditions. Further details of the LSV for $p^{+}-n$ Si photoanode with and without any $\mathrm{MoSe}_{2}$ coverage are shown in Supporting Information, Section 4. It is observed that the $p^{+}-n$ Si photoanode exhibit negligible photocurrent, which is directly related to the rapid surface oxidation of unprotected Si surface. ${ }^{[28]}$ Superior performance was achieved for $\mathrm{MoSe}_{2} / p^{+}-n$ Si photoanodes with $\approx 3 \mathrm{~nm}$ $\mathrm{MoSe}_{2}$. Shown in Figure 3a, the current-onset potential is $\approx 0.3 \mathrm{~V}$ versus $\mathrm{RHE}$, with a nearly light-limited current density $\approx 30 \mathrm{~mA} / \mathrm{cm}^{2}$ measured at $\approx 0.8 \mathrm{~V}$ versus RHE (see Supporting Information, Section 5). The measurement of light-limited current density also suggests that the thin $\mathrm{MoSe}_{2}$ layer can effectively passivate the Si surface to minimize surface recombination. The achievement of high photocurrent density for a photoanode under relatively low bias voltage is essentially required to realize unassisted solar $\mathrm{H}_{2}$ generation when paired with a highperformance photocathode for PEC tandem system. With (a)

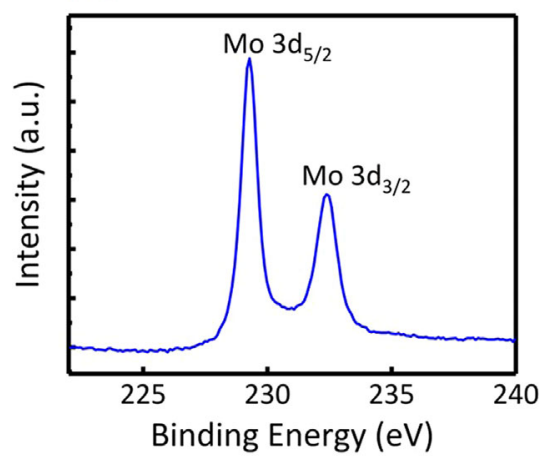

(c)

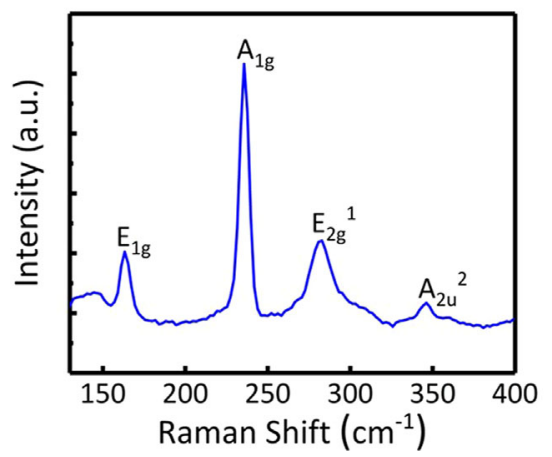

(b)

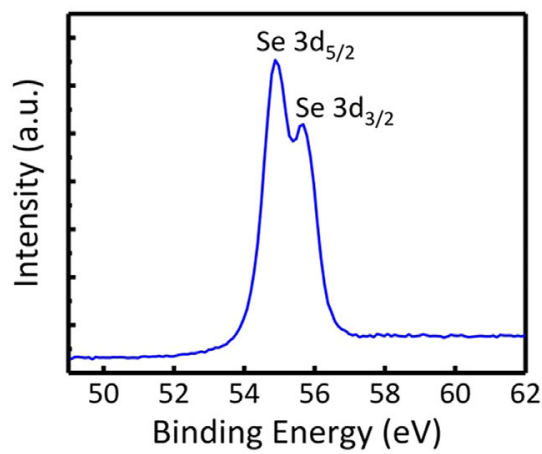

(d)

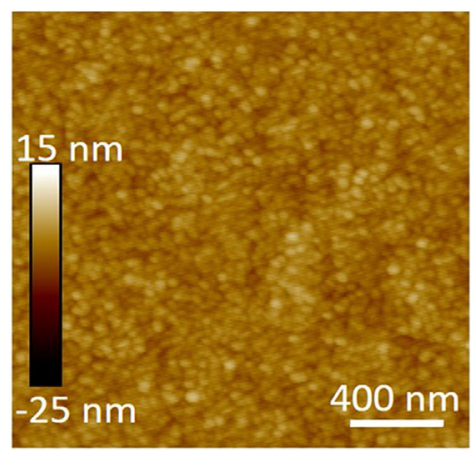

Figure 2. Structural characterization of few-layer $\mathrm{MoSe}_{2}$ grown on $\mathrm{Si}$ substrate. XPS measurements show (a) two peaks at 229.2 and $232.4 \mathrm{eV}$ corresponding to $\mathrm{Mo}^{4+}$ and (b) doublet of 54.9 and $55.6 \mathrm{eV}$ corresponding to $\mathrm{Se}^{2-}$ for $\mathrm{MoSe}_{2}$ film. c) Raman spectra for $\mathrm{MoSe}_{2}$ film showing $E_{1 g}, A_{1 g}, E_{2 g}{ }^{1}$, and $A_{2 u}{ }^{2}$ modes at 163.02, 235.67, 281.89, and $346.18 \mathrm{~cm}^{-1}$, respectively. d) AFM image of $\mathrm{MoSe}_{2}$ surface on Si wafer; scale bar $400 \mathrm{~nm}$. The thickness of $\mathrm{MoSe}_{2}$ layer is $\approx 3 \mathrm{~nm}$. increasing $\mathrm{MoSe}_{2}$ thickness to $\approx 5 \mathrm{~nm}$, the photocurrent density is reduced to $\approx 27 \mathrm{~mA} \mathrm{~cm}^{-2}$, due to the less efficient tunneling of photo-excited holes from Si to electrolyte. It is worth mentioning that the reduction of photocurrent density may be partly related to the increased absorption of $\mathrm{MoSe}_{2}$ protection layer due to the slightly larger thickness. Previous studies have shown that the hole tunneling through the protection layer is extremely sensitive to the layer thickness. ${ }^{[\mathrm{b}]}$ In this study, since the surface roughness is relatively large $(\approx 1-2 \mathrm{~nm})$ for $\mathrm{MoSe}_{2}$ layers, we observed a relatively small difference in the photocurrent density by increasing the thicknesses from 3 to $5 \mathrm{~nm}$. Also for these reasons, it is observed that decreasing the $\mathrm{MoSe}_{2}$ thickness to $\approx 1 \mathrm{~nm}$ leads to negligible photocurrent density, due to the uneven surface coverage and the resulting oxidation of the Si surface. With further increasing the $\mathrm{MoSe}_{2}$ thickness to $\approx 10 \mathrm{~nm}$, both the photocurrent density and current-onset potential become significantly worse, due to the suppressed tunneling for photo-generated holes. In these studies, the underlying $\mathrm{Si}$ wafers are identical and are contacted from the backside. Therefore, the drastically different PEC characteristics are directly related to the thicknesses of $\mathrm{MoSe}_{2}$ protection layer, which provides unambiguous evidence that an optimum thickness of epitaxial $\mathrm{MoSe}_{2}$ can protect the semiconductor photoanode without compromising the extraction of photo-generated holes. Through detailed studies on the $\mathrm{MoSe}_{2}$ growth temperature and in situ annealing conditions (see Supporting Information, Section 2), it was identified that the best performing $\mathrm{MoSe}_{2} / p^{+}-n$ $\mathrm{Si}$ photoanodes could be achieved for $\mathrm{MoSe}_{2}$ thickness $\approx 3 \mathrm{~nm}$ and growth temperature in the range of $200-400^{\circ} \mathrm{C}$.

The ABPE of the photoanode was derived using the Equation (1),

$\eta(\%)=\frac{J\left(E_{\mathrm{rev}}^{0}-V_{\mathrm{RHE}}\right)}{P_{\mathrm{in}}} \times 100$

where $J$ is the photocurrent density, $E_{\text {rev }}^{0}$ is the standard electrode oxidation potential for $\mathrm{Br}$, $V_{\text {RHE }}$ is the applied bias versus RHE, and $P_{\text {in }}$ is the power of the incident light (i.e., $100 \mathrm{~mW}$ $\mathrm{cm}^{-2}$ ). Variations of the ABPE versus applied bias are shown in Figure 3b for $\mathrm{MoSe}_{2} / p^{+}-n \mathrm{Si}$ photoanodes with $\mathrm{MoSe}_{2}$ thicknesses varying from 1 to $10 \mathrm{~nm}$. It is seen that a maximum ABPE of $13.8 \%$ is achieved at $\approx 0.5 \mathrm{~V}$ versus $\mathrm{RHE}$ for $\mathrm{MoSe}_{2} / p^{+}-n$ Si photoanodes with $\mathrm{MoSe}_{2}$ thickness $\approx 3 \mathrm{~nm}$. The maximum ABPE decreases to $\approx 12$ and $2 \%$ with increasing $\mathrm{MoSe}_{2}$ thickness to 5 and $10 \mathrm{~nm}$, respectively, and to negligible values for $\mathrm{MoSe}_{2}$ thicknesses of $1 \mathrm{~nm}$ or less. The reported ABPE of $13.8 \%$ is significantly higher than previously reported TMDC-based photoanode in polyhalide-based redox systems and hole scavenger solutions. ${ }^{[17 b-d, 18,29]}$ However, the cost of using $\mathrm{HBr}$ for solar-to-hydrogen production needs to be analyzed, compared to water splitting. ${ }^{[30]}$ The incident-photon-to-current-efficiency (IPCE) of $\mathrm{MoSe}_{2} / p^{+}-n$ Si photoanode with 
(a)

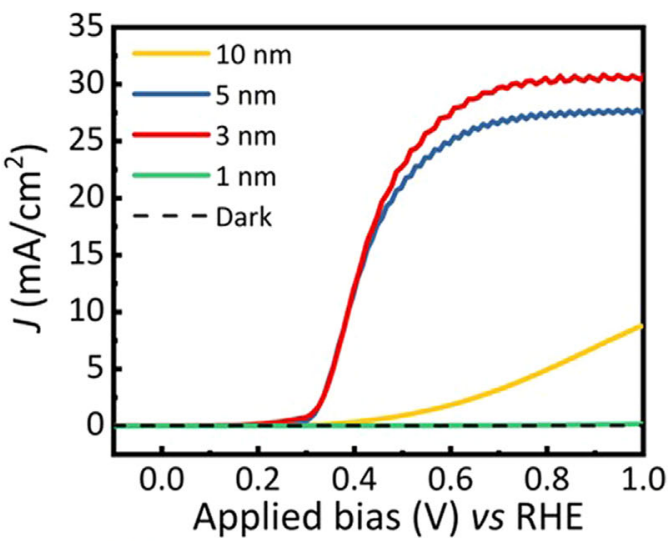

(b)

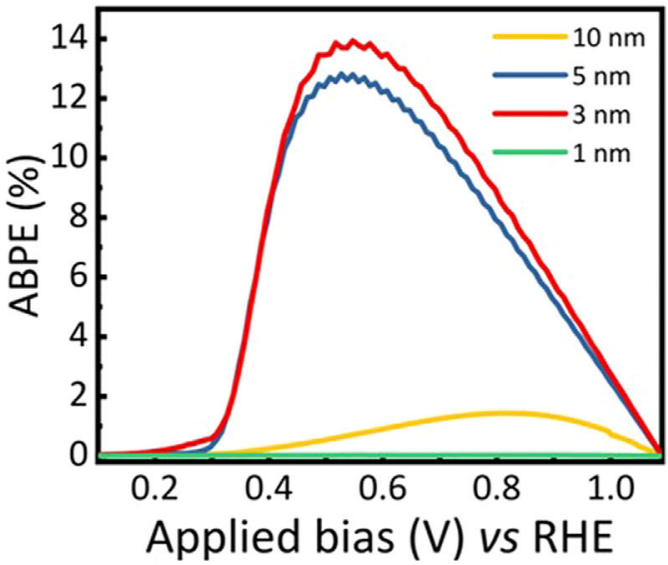

(c)

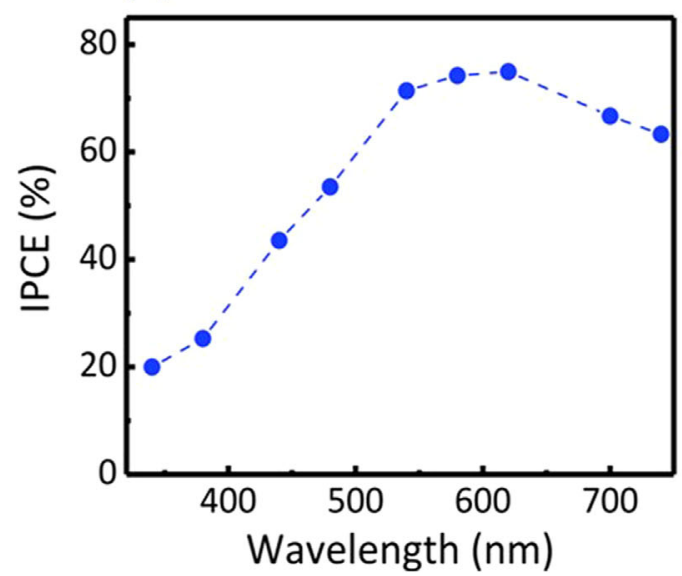

Figure 3. PEC performance characterization of $\mathrm{MoSe}_{2} / p^{+}-n \mathrm{Si}$ photoanode. a) $J-V$ characteristics of $\mathrm{MoSe}_{2} / p^{+}-n$ Si photoanode with $\mathrm{MoSe}_{2}$ thicknesses of $1 \mathrm{~nm}$ (green curve), $3 \mathrm{~nm}$ (red curve), $5 \mathrm{~nm}$ (blue curve) and $10 \mathrm{~nm}$ (yellow curve) under AM 1.5C one sun illumination $(100 \mathrm{~mW}$ $\mathrm{cm}^{-2}$ ) and dark condition (black dashed curve) in $1 \mathrm{M} \mathrm{HBr}$. b) ABPE measurement for $\mathrm{MoSe}_{2} / p^{+}-n \mathrm{Si}$ photoanode with different $\mathrm{MoSe}_{2}$ thicknesses. The highest ABPE of $13.8 \%$ was measured for Si photoanode with $3 \mathrm{~nm} \mathrm{MoSe} \mathrm{N}_{2}$ protection layer at $\approx 0.5 \mathrm{~V}$ versus RHE. c) IPCE of $\mathrm{MoSe}_{2} / p^{+}-n \mathrm{Si}$ photoanode under $\mathrm{AM} 1.5 \mathrm{C}$ one sun illumination $\left(100 \mathrm{~mW} \mathrm{~cm}^{-2}\right)$ in $1 \mathrm{M} \mathrm{HBr}$. The peak value is $\approx 75 \%$ at $620 \mathrm{~nm}$.
$\mathrm{MoSe}_{2}$ thickness $\approx 3 \mathrm{~nm}$ was further measured. The measurement was conducted at $1 \mathrm{~V}$ versus RHE in $1 \mathrm{M} \mathrm{HBr}$ in a three-electrode system. The IPCE was calculated using the Equation (2),

$\operatorname{IPCE}(\%)=1240 \times I /\left(\lambda \times P_{\text {in }}\right) \times 100$

where $I$ is photocurrent density $\left(\mathrm{mA} / \mathrm{cm}^{2}\right), \lambda$ is the incident light wavelength $(\mathrm{nm})$ and $P_{i n}$ is the power density $\left(\mathrm{mW} \mathrm{cm}^{-2}\right)$ of the incident illumination. Shown in Figure $3 \mathrm{c}$, the maximum IPCE is above $70 \%$.

We have further studied the open circuit potential (OCP) of $\mathrm{MoSe}_{2} / p^{+}-n \mathrm{Si}$ photoanodes, which was measured vs RHE under chopped light illumination. A negative shift of the OCP was measured under light illumination, which is characteristic of photoanodes. The OCP ( $E_{\text {ocp }}$ Vs. RHE) of $p^{+}-n$ Si and $\mathrm{MoSe}_{2} /$ $p^{+}-n \mathrm{Si}$ with $\mathrm{MoSe}_{2}$ thickness $\approx 3 \mathrm{~nm}$ is shown in Figure 4a. The

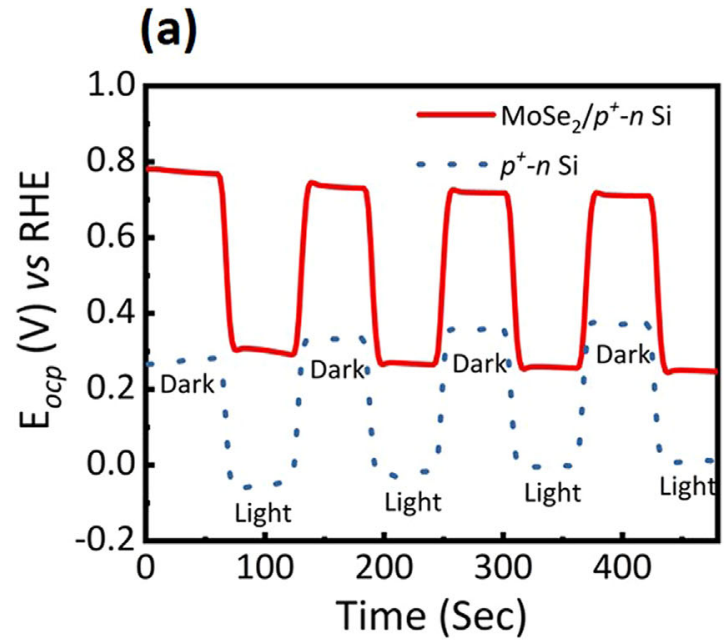

(b)

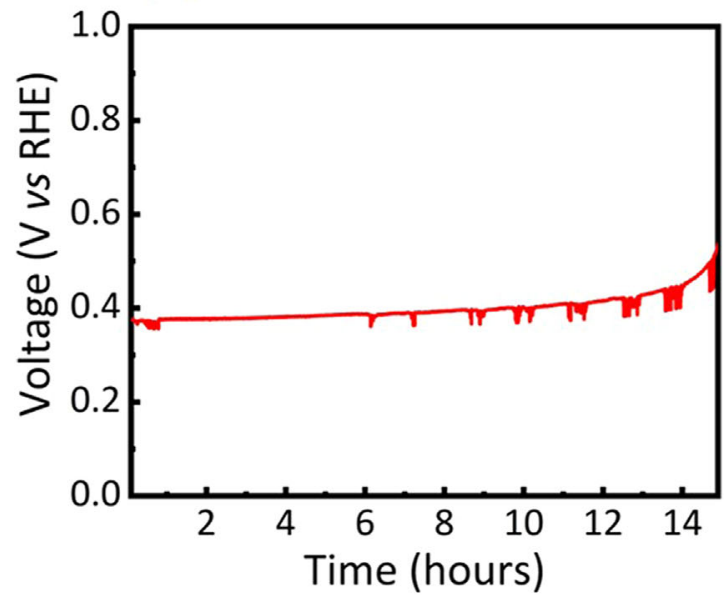

Figure 4. OCP and Stability measurements of $\mathrm{MoSe}_{2} / p^{+}-n$ Si photoanode. a) OCP versus RHE under chopped light illumination. Red curve shows OCP for $\mathrm{MoSe}_{2} / p^{+}-n$ Si photoanode, and dotted blue curve is OCP for $p^{+}-n$ $\mathrm{Si}$ without $\mathrm{MoSe}_{2}$. b) Chronopotentiometry graph shows stable voltage (vs $\mathrm{RHE}$ ) $\approx 0.38 \mathrm{~V}$ for $\approx 14 \mathrm{~h}$ at $\approx 2 \mathrm{~mA} \mathrm{~cm}^{-2}$ under $\mathrm{AM} 1.5 \mathrm{G}$ one sun illumination in $1 \mathrm{M} \mathrm{HBr}$. 
$p^{+}-n$ Si photoanode (dotted blue curve) exhibits a dark potential $\approx 0.3 \mathrm{~V}$ and an illuminated potential $\approx 0 \mathrm{~V}$, with a change in OCP $\approx 0.3 \mathrm{~V}$. The change in OCP under dark and illumination conditions is less than the photovoltage $\approx 0.53 \mathrm{~V}$ for a typical $p^{+}$$n$ Si junction, which is due to the change of potential drop across the Helmholtz layer at the Si/electrolyte interface. $E_{\text {ocp }}$ of the $\mathrm{MoSe}_{2} / p^{+}-n$ Si photoanode (solid red curve) is $\approx 0.3$ and $0.8 \mathrm{~V}$ versus RHE under illumination and dark conditions, respectively. The potential difference under light and dark conditions is $\approx 0.5 \mathrm{~V}$, which is nearly identical to the flat-band potential $\left(V_{\mathrm{fb}}\right)$ derived from the Mott-Schottky measurements (see Supporting Information, Section 6). Moreover, the lightinduced OCP shift $(\approx 0.5 \mathrm{~V})$ for $\mathrm{MoSe}_{2} / p^{+}-n$ Si photoanode is reasonably close to the open circuit voltage expected from the $p^{+}-n$ Si junction. The negligible voltage loss further confirms that the thin $(\approx 3 \mathrm{~nm}) \mathrm{MoSe}_{2}$ layer can effectively protect the $\mathrm{Si}$ surface from oxidation in acidic solution and that photo-excited holes can tunnel efficiently through the $\mathrm{MoSe}_{2}$ layer. Chronovoltammetry experiments were further performed to test the stability of $\mathrm{MoSe}_{2} / p^{+}-n \mathrm{Si}$ photoanode at photocurrent density of $\approx 2 \mathrm{~mA} \mathrm{~cm}^{-2}$ under AM $1.5 \mathrm{G}$ one sun illumination. Shown in Figure $4 \mathrm{~b}$, the voltage stays nearly constant at $\approx 0.38 \mathrm{~V}$ versus RHE, and there is no any apparent degradation under continuous illumination for $\approx 14 \mathrm{~h}$. The chronoamperometry experiment (Supporting Information, Section 7) also showed stable photocurrent density of $\approx 26 \mathrm{~mA} \mathrm{~cm}^{-2}$ for $1 \mathrm{~h}$ at $0.6 \mathrm{~V}$ versus RHE and subsequent XPS measurements on that sample showed Mo:Se ratio of 1:2.

The underlying mechanisms for the dramatically improved performance of Si-based photoanodes are described. The use of a $\mathrm{MoSe}_{2}$ protection layer allows for the efficient tunneling of photo-excited holes from $p^{+}-n$ Si to electrolyte through the $\mathrm{MoSe}_{2}$ barrier, compared to the previously reported wide bandgap, for example, $\mathrm{TiO}_{2}$ protection layer. ${ }^{[8,31]}$ This is evidenced by the very large hole injection efficiency $(>80 \%)$ even at a relatively low potential ( $\approx 0.5 \mathrm{~V}$ vs. RHE) (see Supporting Information, Section 8). Moreover, the $\mathrm{MoSe}_{2}$ layer is sufficiently thin $(\approx 3 \mathrm{~nm})$ to allow for most of the incident light to pass through, thereby leading to a nearly light-limited current density. For a perfect $\mathrm{MoSe}_{2}$ sheet, there are no dangling bonds and surface states, since the lone pair of electrons on chalcogen (Se) atom terminate on the surface. ${ }^{[23 a]}$ Recent first principles calculations have further shown that a perfect $\mathrm{MoSe}_{2}$ sheet is intrinsically chemically inert and can effectively protect against oxidation $^{[21,23 a]}$ and photo-corrosion, ${ }^{[23 a]}$ which explains the dramatically improved performance and stability, compared to a bare $\mathrm{Si}$ photoanode. It is also worthwhile mentioning that the enhanced performance is not likely due to the catalytic property of $\mathrm{MoSe}_{2}$, since the $\mathrm{MoSe}_{2}$ layer showed no activity under dark condition (see Figure S4, Supporting Information, and Figure 3a) and the $1 \mathrm{~nm}$ thickness sample (in Figure 3a) showed very poor light scan. To further improve the device stability, it is essential to eliminate, or minimize the presence of Se vacancy and related defects, which are known to significantly enhance the oxidation effect. ${ }^{[21,32]}$

In conclusion, we have demonstrated that the integration of few-layer $\mathrm{MoSe}_{2}$ can protect the surface of an otherwise unstable Si photoelectrode in corrosive environment, while allowing for efficient electron/hole tunneling between $\mathrm{Si}$ photoanode and solution. The $\mathrm{MoSe}_{2} / p^{+}$- $n$ Si photoanode exhibit remarkable PEC performance, including an excellent current-onset potential of $0.3 \mathrm{~V}$ versus $\mathrm{RHE}$, a light-limited current photocurrent density of $\approx 30 \mathrm{~mA} \mathrm{~cm}^{-2}$ under AM1.5G one sun illumination, an ABPE of $13.8 \%$, and relatively high stability in acidic solution. For future work, it would be important to investigate and optimize the $\mathrm{MoSe}_{2} / \mathrm{Si}$ heterointerface, to engineer the surface properties of $\mathrm{MoSe}_{2}$, and to couple with suitable water oxidation co-catalysts, which will further improve the current-onset potential and enhance the photoanode performance and stability in PEC water splitting. These studies will contribute to the development of low cost, high efficiency, and highly stable Si-based photoelectrodes for solar $\mathrm{H}_{2}$ production.

\section{Experimental Section}

Fabrication of $p^{+}-n$ Si: Double side polished $n$-type Si(100) wafers (WRS Materials, thickness: 254-304 $\mu \mathrm{m}$; resistivity: $1-10 \Omega \cdot \mathrm{cm})$ were spincoated with liquid boron dopant precursor (Futurrex, Inc.) on one side to form the $\mathrm{p}^{+}$-Si emitter and liquid phosphorus dopant precursor (Futurrex, Inc.) on the other side to form the $n^{+}$-Si back field layer. Subsequently, the thermal diffusion process was conducted at $950^{\circ} \mathrm{C}$ for $240 \mathrm{~min}$ under argon gas flow in a furnace. The residue of the precursor was removed in buffered oxide etch solution. To measure the efficiency of the solar cells, metal contacts were made on $n$-side and $p$-side by depositing $\mathrm{Ti} / \mathrm{Au}$ and $\mathrm{Ni} / \mathrm{Au}$ respectively using e-beam evaporator. Shown in Figure S1, Supporting Information, $J_{\text {sc }}$ of the device is $\sim 31 \mathrm{~mA} \mathrm{~cm}^{-2}, V_{\text {oc }}$ is $\approx 0.52 \mathrm{~V}$, and the energy conversion efficiency is $\approx 11 \%$.

$P E C$ measurements: The PEC reaction was conducted in $1 \mathrm{~mol} \mathrm{~L}^{-1} \mathrm{HBr}$ solution using a potentiostat (Gamry Instruments, Interface 1000) with $\mathrm{MoSe}_{2} / p^{+}-n \mathrm{Si}$, silver chloride electrode $(\mathrm{Ag} / \mathrm{AgCl})$, and $\mathrm{Pt}$ wire as the working, reference, and counter electrode, respectively. The working electrode was prepared by cleaving the $\mathrm{MoSe}_{2} / p^{+}-n \mathrm{Si}$ wafer into area sizes of $0.2-1 \mathrm{~cm}^{2}$. A Ga-In eutectic (Sigma-Aldrich) alloy was deposited on the backside of the Si wafer to form ohmic contact, which was subsequently connected to a $\mathrm{Cu}$ wire using silver paste. The entire sample except the front surface was covered by insulating epoxy and placed on a glass slide. A solar simulator (Newport Oriel) with an AM 1.5 G filter was used as the light source, and the light intensity was calibrated to be $100 \mathrm{~mW} \mathrm{~cm}{ }^{-2}$ for all subsequent experiments. The conversion of the $\mathrm{Ag} / \mathrm{AgCl}$ reference potential to $\mathrm{RHE}$ is calculated using the Equation (3),

$E_{(\mathrm{RHE})}=E_{\mathrm{Ag} / \mathrm{AgCl}}+E_{\mathrm{Ag} / \mathrm{AgCl}}^{\circ}+0.059 \times \mathrm{pH}$

where $E_{\mathrm{Ag} / \mathrm{AgCl}}^{\circ}$ is $0.197 \mathrm{~V}$, and $\mathrm{pH}$ of the electrolyte is nearly zero.

$\mathrm{MBE}$ growth of $\mathrm{MoSe}_{2}$ : During the growth process, molybdenum (Mo) was thermally evaporated using an e-beam evaporator (Telemark Inc.) retrofitted in the MBE reaction chamber. We have developed a two-step MBE growth process for $\mathrm{MoSe}_{2}$ thin film. In the first step, the substrate was heated to temperatures in the range of $200-450^{\circ} \mathrm{C}$, and Mo molecular beam was introduced under Se-rich conditions (Se beam equivalent pressure (BEP) of $3.5 \times 10^{-7}$ torr) for $18-180 \mathrm{~min}$, with a deposition rate $\approx 0.01 \mathrm{~A} / \mathrm{s}$ for $\mathrm{MoSe}_{2}$. The resulting $\mathrm{MoSe}_{2}$ thicknesses vary between $1 \mathrm{~nm}$ and $10 \mathrm{~nm}$. In the second step an in situ thermal annealing was performed under Se flux for $10 \mathrm{~min}$ in the temperature range of $200-650^{\circ} \mathrm{C}$ (see Supporting Information, Section 2).

\section{Supporting Information}

Supporting Information is available from the Wiley Online Library or from the author. 


\section{Acknowledgments}

This work is being supported by the Emissions Reduction Alberta (ERA)

\section{Conflict of Interest}

The authors declare no commercial or financial conflict of interest.

\section{Keywords}

hydrogen, photoelectrodes, solar cells, transitional metal dichalcogenides, two-dimensional materials, water splitting

Received: April 20, 2018 Revised: May 4, 2018 Published online: June 6, 2018

[1] S. Chu, A. Majumdar, Nature 2012, 488, 294

[2] a) M. G. Walter, E. L. Warren, J. R. McKone, S. W. Boettcher, Q. X. Mi, E. A. Santori, N. S. Lewis, Chem. Rev. 2010, 110, 6446. b)Y. Hou, X. Zhuang, X. Feng, Small Methods 2017, 1, 1700090. c) B. Parkinson, J. Turner, in Photoelectrochemical Water Splitting: Materials, Processes and Architectures. The Royal Society of Chemistry, Cambridge, UK 2013 Ch. 1, pp. 1-18; d) M. Gratzel, Nature 2001, 414, 338.

[3] a) J. A. Turner, Science 2004, 305, 972; b) N. S. Lewis, D. G. Nocera, Proc. Natl. Acad. Sci. USA 2006, 103, 15729;

[4] S. Hu, C. X. Xiang, S. Haussener, A. D. Berger, N. S. Lewis, Energ. Environ. Sci. 2013, 6, 2984

[5] a) K. Sivula, F. Le Formal, M. Gratzel, ChemSusChem 2011, 4, 432; b) S. Shen, S. A. Lindley, X. Chen, J. Z. Zhang, Energ. Environ. Sci. 2016, 9, 2744.

[6] a) Y. Park, K. J. McDonald, K.-S. Choi, Chem. Soc. Rev. 2013, 42, 2321; b) I. D. Sharp, J. K. Cooper, F. M. Toma, R. Buonsanti, ACS Energy Lett. 2017, 2, 139.

[7] a) M. Li, W. Luo, D. Cao, X. Zhao, Z. Li, T. Yu, Z. Zou, Angew. Chem. Int. Ed. 2013, 52, 11016; b) M. Zhong, T. Hisatomi, Y. Sasaki, S. Suzuki, K. Teshima, M. Nakabayashi, N. Shibata, H. Nishiyama, M. Katayama, T. Yamada, K. Domen, Angew. Chem. Int. Ed. 2017, 56, 4739.

[8] a) S. Hu, M. R. Shaner, J. A. Beardslee, M. Lichterman, B. S. Brunschwig, N. S. Lewis, Science 2014, 344, 1005; b) M. T. McDowell, M. F. Lichterman, A. I. Carim, R. Liu, S. Hu, B. S. Brunschwig, N. S. Lewis, ACS Appl. Mater. Interfaces 2015, 7, 15189.

[9] a) S. Fan, I. Shih, Z. Mi, Adv. Energ. Mater. 2016, 7, 1600952; b) B. AlOtaibi, S. Fan, S. Vanka, M. G. Kibria, Z. Mi, Nano Lett. 2015, 15 , 6821.

[10] a) B. Mei, B. Seger, T. Pedersen, M. Malizia, O. Hansen, I. Chorkendorff, P. C. K. Vesborg, J. Phys. Chem. Lett. 2014, 5, 1948; b) X. H. Zhou, R. Liu, K. Sun, K. M. Papadantonakis, B. S. Brunschwig, N. S. Lewis, Energy Environ. Sci. 2016, 9, 892; c) H. P. Wang, K. Sun, S. Y. Noh, A. Kargar, M. L. Tsai, M. Y. Huang, D. L. Wang, J. H. He, Nano Lett. 2015, 15, 2817.

[11] K. Sun, S. H. Shen, Y. Q. Liang, P. E. Burrows, S. S. Mao, D. L. Wang, Chem. Rev. 2014, 114, 8662.

[12] a) H. Gerischer, Faraday Discuss. Chem. Soc. 1980, 70, 137; b) M. J. Kenney, M. Gong, Y. Li, J. Z. Wu, J. Feng, M. Lanza, H. Dai, Science 2013, 342, 836

[13] a) Y. W. Chen, J. D. Prange, S. Duhnen, Y. Park, M. Gunji, C. E. D. Chidsey, P. C. Mclntyre, Nat. Mater. 2011, 10, 539; b) X. H. Zhou, R. Liu, K. Sun, D. Friedrich, M. T. McDowell, F. Yang, S. T. Omelchenko, F. H. Saadi, A. C. Nielander, S. Yalamanchili, K. M. Papadantonakis, B. S. Brunschwig, N. S. Lewis, Energy Environ. Sci. 2015, 8, 2644; c) G. Xu, Z. Xu, Z. Shi, L. Pei, S. Yan, Z. Gu, Z. Zou, ChemSusChem 2017, 10, 2897; d) K. Sun, M. T. McDowell, A. C. Nielander, S. Hu, M. R. Shaner, F. Yang, B. S. Brunschwig, N. S. Lewis, J. Phys. Chem. Lett. 2015, 6, 592.

[14] B. Guo, A. Batool, G. Xie, R. Boddula, L. Tian, S. U. Jan, J. R. Gong, Nano Lett. 2018, 18, 1516.

[15] R. Fan, W. Dong, L. Fang, F. Zheng, M. Shen, J. Mater. Chem. A 2017, 5,18744

[16] a) X. Xu, G. Zhou, X. Dong, J. Hu, ACS Sustain. Chem. Eng. 2017, 5, 829, b) F. M. Pesci, M. S. Sokolikova, C. Grotta, P. C. Sherrell, F. Reale, K. Sharda, N. Ni, P. Palczynski, C. Mattevi, ACS Catal. 2017, 7, 4990.

[17] a) J. R. McKone, A. P. Pieterick, H. B. Gray, N. S. Lewis, J. Am. Chem. Soc. 2013, 135, 223; b) G. Kline, K. Kam, D. Canfield, B. A. Parkinson, Sol. Energ. Mater. 1981, 4, 301; c) H. J. Lewerenz, A. Heller, F. J. DiSalvo, J. Am. Chem. Soc. 1980, 102, 1877; d) R. Tenne, A. Wold, Appl. Phys. Lett. 1985, 47, 707.

[18] L. P. Bicelli, G. Razzini, Surf. Technol. 1982, 16, 37.

[19] a) X. Yu, M. S. Prevot, N. Guijarro, K. Sivula, Nat. Commun. 2015, 6, 7596; b) Y. Ouyang, C. Ling, Q. Chen, Z. Wang, L. Shi, J. Wang, Chem. Mater. 2016, 28, 4390; c) A. K. Singh, K. Mathew, H. L. Zhuang, R. G. Hennig, J. Phys. Chem. Lett. 2015, 6, 1087;

[20] R. Bourezg, G. Couturier, J. Salardenne, F. Lévy, Phys. Rev. B 1992, 46, 15404.

[21] H. Liu, N. Han, J. Zhao, RSC Adv. 2015, 5, 17572.

[22] L. A. King, T. R. Hellstern, J. Park, R. Sinclair, T. F. Jaramillo, ACS Appl. Mater. Interfaces 2017, 9, 36792.

[23] a) M. Chhowalla, H. S. Shin, G. Eda, L. J. Li, K. P. Loh, H. Zhang, Nat. Chem. 2013, 5, 263; b) N. Balis, E. Stratakis, E. Kymakis, Mater. Today 2016, 19, 580 .

[24] a) E. Xenogiannopoulou, P. Tsipas, K. E. Aretouli, D. Tsoutsou, S. A. Giamini, C. Bazioti, G. P. Dimitrakopulos, P. Komninou, S. Brems, C. Huyghebaert, I. P. Radu, A. Dimoulas, Nanoscale 2015, 7, 7896; b) Y. H. Choi, D. H. Lim, J. H. Jeong, D. Park, K. S. Jeong, M. Kim, A. Song, H. S. Chung, K. B. Chung, Y. Yi, M. H. Cho, ACS Appl. Mater. Interfaces 2017; c) Y.-H. Chang, W. Zhang, Y. Zhu, Y. Han, J. Pu, J.-K. Chang, W.-T. Hsu, J.K. Huang, C.-L. Hsu, M.-H. Chiu, T. Takenobu, H. Li, C.-I. Wu, W.-H.Chang, A. T. S. Wee, L.-J. Li, ACS Nano 2014, 8, 8582; d) X. Lu, M. I. Utama, J. Lin, X. Gong, J. Zhang, Y. Zhao, S. T. Pantelides, J. Wang, Z. Dong, Z. Liu, W. Zhou, Q. Xiong, Nano Lett. 2014, 14, 2419; e) F. S. Ohuchi, B. A. Parkinson, K. Ueno, A. Koma, J. Appl. Phys. 1990, 68, 2168.

[25] D. Tsoutsou, K. E. Aretouli, P. Tsipas, J. Marquez-Velasco, E. Xenogiannopoulou, N. Kelaidis, S. Aminalragia Giamini, A. Dimoulas, ACS Appl. Mater. Interfaces 2016, 8, 1836.

[26] Y. Zhao, H. Lee, W. Choi, W. Fei, C. J. Lee, RSC Adv. 2017, 7, 27969.

[27] a) C. Jung, S. M. Kim, H. Moon, G. Han, J. Kwon, Y. K. Hong, I. Omkaram, Y. Yoon, S. Kim, J. Park, Sci. Rep. 2015, 5, 15313; b) M. I. Utama, X. Lu, D. Zhan, S. T. Ha, Y. Yuan, Z. Shen, Q. Xiong, Nanoscale 2014, 6, 12376; c) D. Nam, J. U. Lee, H. Cheong, Sci. Rep. 2015, 5, 17113; d) P. Soubelet, A. E. Bruchhausen, A. Fainstein, K. Nogajewski, C. Faugeras, Phys. Rev. B 2016, 93, 155407.

[28] A. Q. Contractor, J. O. M. Bockris, Electrochim. Acta 1984, 29, 1427.

[29] a) J. R. McKone, R. A. Potash, F. J. DiSalvo, H. D. Abruna, Phys. Chem. Chem. Phys. 2015, 17, 13984; b) L. A. King, W. Zhao, M. Chhowalla, D. J. Riley, G. Eda, J. Mater. Chem. A 2013, 1, 8935.

[30] B. Mei, G. Mul, B. Seger, Adv. Sustain. Syst. 2017, 1, 1600035.

[31] A. G. Scheuermann, J. P. Lawrence, K. W. Kemp, T. Ito, A. Walsh, C. E. Chidsey, P. K. Hurley, P. C. McIntyre, Nat. Mater. 2016, 15, 99.

[32] J. Gao, B. Li, J. Tan, P. Chow, T. M. Lu, N. Koratkar, ACS Nano 2016 , 10, 2628. 